\title{
МИРОТВОРЧЕСКИЕ ОПЕРАЦИИ
}

\author{
О.Г. Карпович
}

\section{АФГАНИСТАН-2014 ВО ВНЕШНЕПОЛИТИЧЕСКОЙ СТРАТЕГИИ США И КАНАДЫ}

\begin{abstract}
Аннотация. Проблема поддержания международной безопасности на должном уровне в Афганистане не только не теряет свою актуальность, но, напротив, все время обостряется. Во многом это связано с намерением США и их союзников полностью вывести свои военные контингенты из страны к 2014 г. В мире опасаются, что после того, как США уйдут из Афганистана, их место тут же займут талибы - пока что единственная реальная сила, способная взять в свои руки всю полноту политической власти в стране. В способность марионеточного режима Х. Карзая удержаться у власти никто не верит. Афганистан, вернувшийся в состояние полномасштабной гражданской войны, либо вновь перешедший под контроль талибов, может сыграть роль пороховой бочки для региона, где некоторые страны балансируют на грани распада даже в нынешних, относительно спокойных условиях (например, Киргизия и Таджикистан). Фактически многие региональные игроки уже готовятся к вероятному хаосу в регионе и элементом такой подготовки являются, в частности военные маневры, проводимые в рамках ШОС и ОДКБ.

Ключевые слова. Политология, ISAF, США, Канада, Афганистан, национальная безопасность, внешняя политика, международные отношения, конфликт, национальные интересы.
\end{abstract}

$\Pi$ роблема поддержания международной безопасности на должном уровне в Афганистане не только не теряет свою актуальность, но, напротив, все время обостряется. Во многом это связано с намерением США и их союзников полностью вывести свои военные контингенты из страны к 2014 году. В мире опасаются, что после того, как США уйдут из Афганистана, их место тут же займут талибы - пока что единственная реальная сила, способная взять в свои руки всю полноту политической власти в стране. В способность марионеточного режима Х. Карзая удержаться у власти никто не верит.

Афганистан, вернувшийся в состояние полномасштабной гражданской войны, либо вновь перешедший под контроль талибов, может сыграть роль пороховой бочки для региона, где некоторые страны балансируют на грани распада даже в нынешних, относительно спокойных условиях (например, Киргизия и Таджикистан). Фактически многие региональные игроки уже готовятся к вероятному хаосу в регионе и элементом такой подготовки являются, в частности военные маневры, проводимые в рамках ШОС и ОДКБ.

«Афганистан - очень, очень уязвим в настоящее время и будет ещё уязвимее, и даже может погрузиться в хаос и гражданскую войну, если мировая общественность - особенно в Соединенных Штатах, и странах - союзницах по НАТО, таких как Канада, отвернётся от него», - такое жёсткое предупреждение было сделано группой известных афганских деловых и политических лидеров в Галифаксе во время Форума по международной безопасности ${ }^{1}$.

«Афганистан требует много ресурсов и терпения со стороны международного сообщества», - сказал Абдул Рахим Вардак, бывший министр обороны и текущий советник афганского президента Хамида Карзая. - «К сожалению, талибы и их сторонники считали с самого начала, что рано или поздно у международного сообщества не хватит терпения, и они уйдут, и именно поэтому талибы уже давно начали тщательно готовиться к этому моменту. Поэтому, во избежание их активности, мы надеемся, что международная поддержка будет продолжена»².

Вместе с тем, объявленный вывод войск США и их союзников из Афганистана не означает ликвидации американского военного присутствия в этой стране и об этом вполне однозначно заявлялось официальными лицами США. 2014 г. должен стать лишь датой, когда афганские силовые структуры смогут взять на себя полностью задачи контроля над территорией и борьбы с талибами.

Предполагается, что при этом они будут получать масштабную материально-техническую и финансовую поддержку США, в Афганистане будут по-прежнему

1 URL: http://news.nationalpost.com/2012/11/18/afghanistanwill-descend-into-chaos-and-civil-war-unless-the-international-community-remains-committed-there-forum-panel/?utm source $=$ dlvr.it\&utm_medium $=$ twitter

2 Там же. 


\section{Миротворческие операции / Peace-keeping operations}

действовать спецслужбы и силы спецназначения США и их союзников ${ }^{3}$. Это продиктовано необходимостью сдерживания угроз международной безопасности, проистекающих из этого региона.

С. Мохсени, медиамагнат из Ближнего Востока, чья компания «Moby Group» владеет несколькими телекомпаниями в Афганистане, в этой связи заявил: «Если мировое сообщество решиться пренебречь Афганистаном и Пакистаном, то в ближайшие годы следует ожидать появление новых проблем мирового масштаба. Регион, имеющий такие угрозы, как ядерное оружие, наркотики и терроризм, не должен оставаться без присмотра. Вы должны задуматься о последствиях. Я думаю, это очень важно для политического руководства в таких странах, как, например, Канада, чтобы правительство смогло доходчиво объяснить своему населению о важности проблем Афганистана» ${ }^{4}$.

«Это очень просто сделать - вывести войска из Афганистана - прикрывшись тем, что состояние мировой экономики нельзя назвать стабильным. Однако следует также задуматься над тем, как это может отразиться на мировой безопасности и экономике. Помните, что когда в последний раз американцы ушли из Афганистана, мы увидели 11 сентября 2001 года?» также отметил С. Мохсени ${ }^{5}$.

Ближайший стратегический союзник США - Канада - уже закончила свою пятилетнюю боевую миссию в провинции Кандагар. Однако на сегодняшний день более 900 канадских военнослужащих по-прежнему находятся в столице страны - Кабуле, чтобы продолжить обучение афганских солдат и полицейских. До марта 2014 г. Канадой запланирован полный вывод войск из Афганистана, до начала выборов в Афганистане в 2013 г.

Другие западные страны также проводят свёртывание своей военной миссии. Соединённые Штаты заявили, что выведут свои войска - 67 тысяч солдат - к 2014 г., хотя "небольшой отряд", состоящий из военных инструкторов и советников, а также «борцов» из антитеррористических подразделений специального назначения, все же останется в Афганистане 6 .

Как сообщают источники, близкие к Министерству обороны Канады, канадская армия изо всех сил старается сохранить на должном уровне свои разведывательные возможности, спасая от разрушения систему

\footnotetext{
Кашин В. Проблема вывода войск из Афганистана сохраняет актуальность // URL: http://www.ru.journal-neo.com

4 URL: http://news.nationalpost.com/2012/11/18/afghanistanwill-descend-into-chaos-and-civil-war-unless-the-international-community-remains-committed-there-forum-panel/?utm source $=$ dlvr.it\&utm_medium $=$ twitter

5 Там же.

6 Васильев A.M. P.S. Боль Афганистана // Азия и Африка сегодня. 2010. №2. С. 44-46.
}

военной разведки, а также способность сдерживания и отражения шпионских атак в условиях сокращения бюджета данного ведомства7.

В рапорте, подготовленном для высших военных чиновников Канады, есть информация о том, что канадское высшее военное командование рекомендовало офицерам военной разведки постоянно находиться в высокой степени готовности к развёртыванию канадских войск за рубежом.

Из документов, полученных канадским информационным агентством The Canadian Press в соответствии с законом о доступе к информации, также явствует, что армия пытается защитить свою разведывательную структуру, занимающуюся сбором и анализом разведданных на основе информации из общедоступных источников и от сведущих людей, известную под названием HUMINT, а также улучшить возможности контрразведки ${ }^{8}$.

С окончанием войны в Афганистане и сокращением оборонного бюджета, у канадских военных возникают опасения того, что данные разведывательные агентства могут подвергнуться деградации. Поскольку, в общей сложности, бюджет Министерства обороны Канады был урезан на 22\%.

Между тем, во время своего выступления перед сенатским Комитетом безопасности и обороны командующий канадской армией генерал-лейтенант Питер Девлин заявил, что он перевёл из разных частей армии 1500 резервистов в такие военные структуры, как военная разведка, а также службы, занимающиеся исследованием, кроме всего прочего, самодельных взрывных устройств, вертолётов и беспилотных летательных аппаратов.

Насколько пополнение кадрового состава разведывательных органов благотворно сказалось на улучшении ситуации с модернизацией внутри разведслужб, остаётся пока неясным, однако, согласно документам, кадровый вопрос там стоял весьма остро.

«За время проведения Канадой военных операций за рубежом, возросла наша убежденность в том, что эффективность боевых действий сухопутных войск, развёрнутых, в частности, (цензура) напрямую зависит от того, насколько развиты и хорошо организованы разведывательные службы, занимающиеся сбором информации из всевозможных источников", - говорится в источниках, близких к Министерству обороны Канады ${ }^{9}$.

Канадская армия с первых же дней своего присутствия в Кандагаре в 2005 г. попала в затруднительное положение, поскольку у неё не было действующей раз-

\footnotetext{
URL: http://www.ctvnews.ca/canada/army-struggling-to-retain-intelligence-capabilities-documents-reveal-1.1081494

8 URL: http://www.thecanadianpress.com/

9 URL: http://www.ctvnews.ca/canada/army-struggling-to-retain-intelligence-capabilities-documents-reveal-1.1081494
} 


\section{Международные отношения International Relations}

ведывательной службы, способной собирать информацию, а также не было специалистов, умеющих допрашивать пленных и заключённых.

Как стало известно из тех же источников, агенты канадской службы безопасности и разведки были доставлены из Канады в Афганистан для того, чтобы помогать дислоцировавшейся под Кандагаром канадской военной базе допрашивать пленных талибов. С момента, когда офицерами военной разведки был приобретён соответствующий опыт, они сами занимались проведением допросов.

Военные НАТО, как и канадские военные, сходятся во мнении, что мало кто ожидал такого интенсивного натиска талибов, каким он был весной 2006 г. ${ }^{10}$ После того, как Канада завершила свою миссию в Афганистане летом 2011 г., отставной генерал Уолт Натынчик в то время начальник штаба обороны, - отозвался о разведке как о сугубо неточной науке, но также не забыл упомянуть о её преимуществах.

«Мы - не первые, кто пришёл к таким выводам, что разведка - неточная наука, поскольку разведка никогда не была совершенной», - сказал генерал У. Натынчик в одном из своих последних интервью канадскому информационному агентству The Canadian Press ${ }^{11}$.

«Нашим ребятам без профессиональной помощи разведслужб приходилось очень туго, вы даже не можете себе представить, насколько им было тяжело действовать без поддержки разведывательной структуры, которая была жизненно необходима в борьбе с повстанцами», - добавил он ${ }^{12}$.

По информации из тех же источников стало известно, что союзные войска не сталкивались с проблемой нехватки разведывательных данных, поскольку до этой миссии в Кандагаре они уже принимали участие в вооружённых конфликтах на Балканах, в Северной Ирландии, Косово, Ираке и Афганистане, и тем самым не только приобрели там опыт, но также сделали деятельность своих разведывательных служб намного эффективнее.

Служба контрразведки Министерства вооружённых сил Канады представляет собой совместное подразделение, которое расследует угрозы национальной безопасности. Согласно источникам, армия надеется создать своё собственное, независимое разведывательное подразделение, сходное с Корпусом морской пехоты США.

Канадский военно-морской флот также решился на преобразование своего разведывательного подразделения. С 2010 года в ВМФ Канады проводились реформы, по завершению которых на кораблях, базирующихся за рубежом, должно было быть больше офицеров разведки, однако в рамках сдерживания бюджетных расходов Министерство обороны Канады приостановило процесс реформирования.

\section{Источники:}

1. Васильев А.М. Р.S. Боль Афганистана. // Азия и Африка сегодня. - 2010. - №2. - С. 44-46.

2. Афганистан и безопасность Центральной Азии. Вып. 3 / под ред. А.А. Князева. - Бишкек, Душанбе, 2006. - 330 с.

3. В. Кашин. Проблема вывода войск из Афганистана сохраняет актуальность // URL: http://www.ru.journal-neo.com

4. URL: http://www.thecanadianpress.com/

5. URL: http://www.ctvnews.ca/canada/troops-ready-eager-for-new-overseas-missions-natynczyk-1.869823

6. URL: http://www.ctvnews.ca/canada/army-struggling-to-retain-intelligence-capabilities-documents-reveal-1.1081494

7. URL: http://news.nationalpost.com/2012/11/18/afghanistan-will-descend-into-chaos-and-civil-war-unless-theinternational-community-remains-committed-there-forum-panel/?utm_source=dlvr.it\&utm_medium=twitter

\section{References (transliteration):}

1. Vasil'ev A.M. P.S. Bol' Afganistana. // Aziya i Afrika segodnya. - 2010. - № 2. - S. 44-46.

2. Afganistan i bezopasnost' Central'noi Azii. Vyp. 3 / pod red. A.A. Knyazeva. - Bishkek, Dushanbe, 2006.

3. Kashin V. Problema vyvoda voisk iz Afganistana sohranyaet aktual'nost'. http://www.ru.journal-neo.com

4. URL: http://www.thecanadianpress.com/

5. URL: http://www.ctvnews.ca/canada/troops-ready-eager-for-new-overseas-missions-natynczyk-1.869823

6. URL: http://www.ctvnews.ca/canada/army-struggling-to-retain-intelligence-capabilities-documents-reveal-1.1081494

7. URL: http://news.nationalpost.com/2012/11/18/afghanistan-will-descend-into-chaos-and-civil-war-unless-theinternational-community-remains-committed-there-forum-panel/?utm_source=dlvr.it\&utm_medium=twitter

\footnotetext{
10 Афганистан и безопасность Центральной Азии. Вып. 3 / под ред. А.А. Князева. Бишкек, Душанбе, 2006. 330 с.

11 URL: http://www.thecanadianpress.com/
}

12 URL: http://www.ctvnews.ca/canada/troops-ready-eager-fornew-overseas-missions-natynczyk-1.869823 